\section{Utilization of health services for skin disorders during military operations. A popula- tion-based study}

\author{
Amir Horev, ${ }^{1,2}$ Shanny Edan-Reuven, ${ }^{2}$ \\ Ron Eshel, ${ }^{2}$ Lena Novack ${ }^{2,3}$ \\ ${ }^{1}$ Pediatric Dermatology Service, Soroka \\ University Medical Center, Beer-Sheva; \\ ${ }^{2}$ Faculty of Health Sciences, Ben-Gurion \\ University of the Negev; ${ }^{3}$ Negev \\ Environmental Health Research \\ Institute, Soroka University Medical \\ Center, Beer-Sheva, Israel
}

\begin{abstract}
In addition to the immediate casualties of armed conflicts, their indirect impact may bring even more damage by causing malfunctioning of health systems and impaired access to diagnosis and treatment. We conducted a population-based study, to assess the utilization rates of health services due to skin disorders, among civilians exposed to missile attacks and siren alarms during three military operations in Israel. The study was designed as a natural experiment, whereas periods of military operations were compared to the non-military times. During the military operations, when sirens and missiles were an everyday experience, the number of visits to dermatologists was 1.07-1.16 times lower [Relative Risk (RR) $=0.86-0.92$ ] as compared to the non-military periods, especially evident for patients residing closer to the military zone, where it dropped almost 2folds $(\mathrm{RR}=0.52)$. Although perceived nonurgent in their majority, the routine care should not be delayed to prevent more serious skin conditions.
\end{abstract}

\section{Introduction}

Immediate casualties are the inevitable toll of most armed conflicts. In addition to the direct damage of war on the population health, its indirect influence might be of even higher importance. ${ }^{1}$ A review of the population health in Iraq over the 40 years of continual military operations since $1980^{2}$ revealed a substantial harm to public health through disruption to health systems and malfunctioning of health workers, impaired access to diagnosis and treatment and reduced availability of medicines. Similar reports have been published on the war in Syria $^{3}$ and more. The profound adverse effects are poorly documented, as in the case with Iraq, ${ }^{4}$ and rarely addressed by the parties involved.

The Israeli-Palestinian conflict has profoundly impacted the population health on both sides ever since 1948. In the last decades, the conflict has been managed mainly by military operations lasting from few days to few months, whereas the civilians residing close by the war zone are exposed to intense rocket missile attacks and siren alarms. Stressful conditions have been found to contribute to the onset and exacerbation of a wide array of skin diseases, ${ }^{5,6}$ e.g. psoriasis, ${ }^{7,8}$ atopic and seborrheic dermatitis, ${ }^{9-11}$ alopecia areata $^{12}$ and acne vulgaris. ${ }^{13}$ While we would expect an increase in seeking medical help during the military operations in the region, this very fact may obstruct the patients' access to health services.

In the current analysis, we performed a population-based study evaluating the association between military operations in the region and utilization of health services for skin disorders.

\section{Materials and Methods}

The study was designed as a natural experiment, in which the population was subjected to the military operations in the region. The institutional review board approved the study after complying with the ethical requirements of the 1964 Helsinki Declaration and the requirements set for by the 1975 Helsinki Declaration and 2013 revision.

\section{Study population}

We included all adults and children insured by Clalit HMO covering approximately $70 \%$ of the local population who resided in the southern part of Israel, and were diagnosed with skin disorders between the years 2007-2015. We extracted all relevant demographic and medical history information recorded by the Clalit HMO primary care physicians and/or the Admission-Discharge-Transfer (ATD) hospital system of the Soroka University Medical Center (SUMC). At the time of the study, Clalit HMO did not offer teledermatology services. The patient population was identified using ICD9 codes with regard to pre-determined dermatological disorders (Supplementary Table 1). All relevant diagnoses were made by the patient's primary physician or dermatologist. Patients with any history of an ICD9 diagnosis of anxiety (300.XX, 308-309.XX) were excluded from the study records.
Correspondence: Amir Horev, Soroka University Medical Center, Beer-Sheva, Israel Tel.: +972-8-6400653 - Fax: +972-8-6768861 E-mail: amirhor@clalit.org.il

Key words: Armed conflicts; dermatology; skin disorders; health services utilization.

Contributions: Amir Horev and Shanny EdanReuven contributed equally to the study.

Conflicts of interest: The authors declare no potential conflict of interest.

Received for publication: 30 May 2020.

Accepted for publication: 18 October 2020.

This work is licensed under a Creative Commons Attribution-NonCommercial 4.0 International License (CC BY-NC 4.0).

C Copyright: the Author(s), 2020

Licensee PAGEPress, Italy

Dermatology Reports 2020; 12:8648

doi:10.4081/dr.2020.8648

Utilization of the health services due to skin disorders were defined as events in the study and were determined for the following domains: i) Dermatology-related physician visits (primary physician, dermatologist, or visits to local dermatology clinic); ii) Hospitalizations in a dermatology department; iii) Purchase of pre-defined physician-prescribed dermatological systemic and topical medications; iv) Skin biopsies; v) Emergency department visits due to a dermatological-related condition.

\section{Definition of exposure to military operations}

The siren alerts and rocket fire were more intense and frequent during the military operations, featured by a daily fire exchange between Israel and Gaza. These periods therefore signified an exposure to military operations and were compared to the rest of the days in the study period. Three military operations were conducted in the area during the study period: the "Cast Lead" operation which lasted 22 days between December 2008-January 2009, the "Pillar of Defense" operation which lasted eight days in November 2012, and the "Protective Edge" operation which lasted 50 days between July-August 2014.

Likewise, each participant was defined by his/her geographic proximity to the military operations in the Gaza Strip, and categorized in the groups of within 0-7, 7-20, 20-30, and 30-40 km from there. This division corresponds to the emergency alert system warning issued 15 seconds, 30, 60, and 
90 seconds before an actual airstrike, at which time the residents are required to find a shelter.

\section{Statistical analysis}

The results are described by mean \pm Standard Deviation (SD), Interquartile Range (IQR), and as percentages for categorical data. We analyzed the daily number of events during the military operations, within 2 weeks and 3-4 before the operation onset and post-operation. The study periods around military operations were compared to the non-military times, serving as a reference. Multivariate analysis was performed using Generalized Linear Models (GLM) with an outcome variable of counts defined by Poisson distribution, and scaled by deviance to address a possible over-dispersion of the outcome. The point estimates of an association were expressed by Relative Risks (RRs). We estimated an impact of the time category relative to an operation onset and duration while adjusting for average weekly temperature, average weekly humidity, a time trend presuming an increased utilization of health system over time and harmonic (sin, cos) functions of the consecutive day number. The last accounted for the seasonality of the counts assuming fluctuations featuring different seasons. Adjustment for humidity and temperature was attempted by using a weekly average temperature and humidity estimates as reported by the meteorological stations at the study region and assigned to each participant using their residential address. We did not adjust to meteorology in the final models as they were not independently associated with any of the outcomes after controlling for seasonality.

We repeated the main analysis in strata of proximity to the Gaza Strip, i.e. 0-7, 7$20,20-30$ and $30-40 \mathrm{~km}$, to ascertain a doseresponse relationship in the magnitude of the possible impact of the gravity of the war conditions on seeking medical help.

\section{Subgroup and specificity analysis}

i) Medication purchases are more accessible during military operations, as opposed to physicians' visits that are likely to be canceled on days of a national emergency. Hence, the patients' behavior with regards to medications was investigated separately, since it is expected to be less affected by the war conditions in the country, as compared to other scheduled activities like appointments. ii) Study outcomes were presented separately by patients' chronic skin disorders, which may vary in terms of its severity and urgency.

Statistical analyses were conducted using IBM SPSS Statistics version 24 (IBM, Armonk, NY, US), with statistical significance set a priori at $\leq 0.10$ (2-tailed) for all calculations. Due to the exploratory nature of our analysis, no alpha-correction was applied despite multiple comparisons performed in the study.

\section{Results}

Our study identified 1,200,610 events of subjects over the study period 1.1.200731.12.2015. The average age of patients treated for a dermatologic condition during the study period was $31.0 \pm 23.5$ years. Of the 127,786 subjects in the study population, $54.3 \%$ were women, about $80 \%$ were born in Israel, and the median Socioeconomic Status (SES), was 6 with an IQR ranging between 0-10 in an SES score (Table 1). The mean follow-up time in the study population was $107.5 \pm 5.6$ (months), with an average of $1.1 \pm 1.5$ events per one year of follow up (where an event was defined as a utilization of health services due to a skin disorder). The most frequent skin disorders were atopic dermatitis and other (seborrheic, erythemato-squamous) dermatitis, psoriasis, and diseases of sebaceous glands, such as acne.
Medication purchase was the most frequent encounter with the health system (close to $60 \%$ ), followed by dermatologists' appointments (close to 40\%), and ER visits, hospitalizations, and biopsies - all adding up to a less than $1 \%$ of all events (Table 2). We therefore focused the rest of our analysis on medications' purchases and appointments. When compared to days without military operations, the frequency of health services utilization was not different on the days of a military operation, or prior or post-military operation, although nominally higher during the 2 weeks post-operation.

The number of visits was lower during the time of military operation for visits related to acne, atopic dermatitis, and urticarial. Inspection of risk estimates reveals a pattern common to all types of morbidities (Table 2). Specifically, the utilization of services was relatively low during the military operations $(\mathrm{RR}<1)$ and high within the next 2 weeks following the operation ( $R R>1)$. During the consecutive 3-4 weeks post-operation, the utilization is rebounded by decreasing visits counts on most occasions $(\mathrm{RR}<1)$. We repeated the analysis in strata of proximity to the Gaza Strip, assuming that the effect of military operations would be higher for patients residing close to the military actions and have less than 30 seconds to find shelter before an airstrike occurs (Table 3). Indeed, the association among atopic and seborrhetic dermatitis and urtricaria patients residing close to the military zone $(0-7 \mathrm{~km})$ appeared to be of higher magnitude as compared to patients residing relatively far $(30-40 \mathrm{~km})$, i.e., $\mathrm{RR}=0.70$ ( $\mathrm{p}$-value $=0.041), \mathrm{RR}=0.63(\mathrm{p}$ value $=0.031)$ and $\mathrm{RR}=0.52 \quad(\mathrm{p}-$ value $=0.001$ ), respectively, as compared to RRs close to 1 in more distant from war areas. A dose-response pattern is evident, while most morbidities unwire affected by the distance from the military zone.

Table 1. Events count by the study periods.

\begin{tabular}{|c|c|c|c|c|c|}
\hline \multirow{2}{*}{ Type of Event } & \multirow[b]{2}{*}{$\begin{array}{l}\text { Event Count on days } \\
\text { without military } \\
\text { operations } \\
\text { (1165342) }\end{array}$} & \multicolumn{3}{|c|}{ On the days of military operation } & \multirow[b]{2}{*}{$\begin{array}{l}\text { "Protective edge" operation, } \\
50 \text { days } \\
\text { l-Aug } 2014 \\
\text { (20607) }\end{array}$} \\
\hline & & All operations & $\begin{array}{l}\text { "Cast lead" operation, } \\
22 \text { days Dec } 2008 \text { - } \\
\text { Jan } 2009 \\
(6622)\end{array}$ & $\begin{array}{l}\text { Pilar of defense" operation } \\
\text { " } 8 \text { days in } \\
\text { Nov } 2012 \\
(4876)\end{array}$ & \\
\hline Biopsy & $0.0(319)$ & $0.0(13)$ & $0.0(3)$ & $0.0(0)$ & $0.0(10)$ \\
\hline Emergency Room Visit & $0.1(1243)$ & $0.2(52)$ & $0.0(0)$ & $0.1(4)$ & $0.2(48)$ \\
\hline Hospitalization & $0.0(401)$ & $0.0(9)$ & $0.0(1)$ & $0.0(2)$ & $0.0(6)$ \\
\hline Purchase of Prescription Drug & $59.2(689725)$ & 59.8 (19198) & $60.1(3977)$ & $62.2(3034)$ & $59.1(12187)$ \\
\hline Physician Appointment & $40.6(473654)$ & $40.0(12833)$ & $39.9(2641)$ & $37.7(1836)$ & $40.5(8356)$ \\
\hline
\end{tabular}




\section{Discussion}

In the current natural experiment analysis, we investigated whether exposure of the population to military operations is associated with utilization of health services and seeking medical help for skin disorders. During the different periods of military operations in Israel, when sirens and missiles were an everyday experience, the count of physicians' visits due to skin disorders in southern Israel was lower as compared to the non-military periods, especially evident for patients with diagnoses of acne, atopic dermatitis, urticarial and nevus, and for subjects residing closer to the military zone. The decreased visits' counts due canceled appointments and delayed medications' purchases due to closed pharmacies were most probably made up later during

Table 2. An association between periods around military operations and utilization of health services, results of a multivariable analysis.*

\begin{tabular}{|c|c|c|c|c|c|c|}
\hline \multirow[b]{2}{*}{$\begin{array}{l}\text { Patients' diagnosis } \\
\text { at the visit }\end{array}$} & \multicolumn{5}{|c|}{ Estimates of the association expressed as RR ( $p$-value $)^{* *}$} & \multirow[b]{2}{*}{$\begin{array}{l}\text { Weeks 3-4 post } \\
\text { military operation }\end{array}$} \\
\hline & $\begin{array}{l}\text { Non-military } \\
\text { operation period } \\
\text { (Reference) }\end{array}$ & $\begin{array}{c}\text { Weeks } 3-4 \text { before } \\
\text { a military } \\
\text { operation }\end{array}$ & $\begin{array}{l}\text { Weeks 1-2 prior } \\
\text { to a military } \\
\text { operation }\end{array}$ & $\begin{array}{c}\text { During a military } \\
\text { operation }\end{array}$ & $\begin{array}{l}\text { Weeks } 1-2 \text { post } \\
\text { military operation }\end{array}$ & \\
\hline $\begin{array}{l}\text { Any event of health } \\
\text { system utilization }\end{array}$ & 1 & $1.06(0.354)$ & $1.03(0.631)$ & $0.95(0.319)$ & $1.06(0.365)$ & $1.00(0.978)$ \\
\hline Medications' purchase & 1 & $1.05(0.432)$ & $1.02(0.747)$ & $0.96(0.413)$ & $1.05(0.476)$ & $1.00(0.978)$ \\
\hline Visits to a dermatologist & 1 & $1.07(0.292)$ & $1.05(0.510)$ & $0.94(0.235)$ & $1.08(0.259)$ & $0.99(0.917)$ \\
\hline \multicolumn{7}{|c|}{ Visits to a dermatologist by diagnosis: } \\
\hline Acne & 1 & $1.05(0.552)$ & $1.10(0.251)$ & $0.87(0.037)$ & $1.05(0.590)$ & $0.94(0.484)$ \\
\hline Atopic dermatitis & 1 & $1.03(0.772)$ & $1.00(0.963)$ & $0.86(0.038)$ & $1.05(0.619)$ & $0.94(0.496)$ \\
\hline Seborrheic dermatitis & 1 & $1.12(0.198)$ & $0.91(0.320)$ & $0.91(0.173)$ & $1.07(0.420)$ & $0.88(0.183)$ \\
\hline Psoriasis & 1 & $1.16(0.148)$ & $1.11(0.331)$ & $0.92(0.293)$ & $1.12(0.277)$ & $1.12(0.290)$ \\
\hline Urticaria & 1 & $1.08(0.386)$ & $1.08(0.393)$ & $0.83(0.007)$ & $0.99(0.909)$ & $1.01(0.879)$ \\
\hline Nevus & 1 & $1.12(0.317)$ & $1.26(0.025)$ & $0.85(0.053)$ & $1.10(0.394)$ & $1.02(0.892)$ \\
\hline
\end{tabular}

${ }^{*}$ Estimates are adjusted to linear trend, annual and weekly seasonality and humidity; ${ }^{*}$ Estimates express a multiplicative effect of the time period at study as compared to the non-military time.

Table 3. An association between periods around military operations and number of physicians' visits by distance from Gaza Strip, results of a multivariable analysis.*

\begin{tabular}{|c|c|c|c|c|c|c|}
\hline $\begin{array}{l}\text { Dermatologic } \\
\text { condition related } \\
\text { to the visit }\end{array}$ & $\begin{array}{l}\text { Estimate } \\
\text { Non-military } \\
\text { operation period } \\
\text { (Reference) }\end{array}$ & $\begin{array}{c}\text { of the association e } \\
\text { Weeks } 3-4 \text { before } \\
\text { a military } \\
\text { operation }\end{array}$ & $\begin{array}{c}\text { ressed as RR ( } \mathrm{p} \text {-val } \\
\text { Weeks 1-2 before } \\
\text { a military } \\
\text { operation }\end{array}$ & $\begin{array}{l}\text { During a military } \\
\text { operation }\end{array}$ & $\begin{array}{l}\text { Weeks } 1-2 \text { post- } \\
\text { military operation }\end{array}$ & $\begin{array}{l}\text { Weeks } 3-4 \text { post- } \\
\text { military operation }\end{array}$ \\
\hline $\begin{array}{l}\text { Acne } \\
\qquad \begin{array}{l}0-7 \mathrm{~km} \\
7-20 \mathrm{~km} \\
20-30 \mathrm{~km} \\
30-40 \mathrm{~km}\end{array}\end{array}$ & $\begin{array}{l}1 \\
1 \\
1 \\
1\end{array}$ & $\begin{array}{l}0.77(0287) \\
1.22(0.086) \\
0.82(0.220) \\
1.11(0.302)\end{array}$ & $\begin{array}{l}1.19(0.385) \\
1.28(0.028) \\
1.04(0.787) \\
1.00(0.964)\end{array}$ & $\begin{array}{l}0.92(0612) \\
0.75(0.012) \\
1.04(0.692) \\
0.84(0.035)\end{array}$ & $\begin{array}{l}1.03(0.885) \\
1.05(0.700) \\
0.89(0.444) \\
1.12(0.245)\end{array}$ & $\begin{array}{l}0.88(0.4570) \\
0.87(0.285) \\
0.86(0.328) \\
1.03(0.735)\end{array}$ \\
\hline $\begin{array}{l}\text { Atopic dermatitis } \\
0-7 \mathrm{~km} \\
7-20 \mathrm{~km} \\
20-30 \mathrm{~km} \\
30-40 \mathrm{~km}\end{array}$ & $\begin{array}{l}1 \\
1 \\
1 \\
1\end{array}$ & $\begin{array}{l}1.04(0.837) \\
1.17(0.226) \\
0.88(0.383) \\
1.03(0.770)\end{array}$ & $\begin{array}{l}1.03(0.873) \\
0.83(0.244) \\
0.95(0.736) \\
1.11(0.336)\end{array}$ & $\begin{array}{l}0.70(0.041) \\
0.83(0.090) \\
0.94(0.528) \\
0.86(0.098)\end{array}$ & $\begin{array}{l}1.17(0.407) \\
0.97(0.823) \\
1.08(0.560) \\
1.05(0.681)\end{array}$ & $\begin{array}{l}0.77(0.246) \\
0.79(0.132) \\
1.04(0.758) \\
0.99(0.894)\end{array}$ \\
\hline $\begin{array}{l}\text { Seborrheic dermatitis } \\
\quad 0-7 \mathrm{~km} \\
7-20 \mathrm{~km} \\
20-30 \mathrm{~km} \\
30-40 \mathrm{~km}\end{array}$ & $\begin{array}{l}1 \\
1 \\
1 \\
1\end{array}$ & $\begin{array}{l}1.34(0.155) \\
0.96(0.789) \\
1.14(0.415) \\
1.18(0.147)\end{array}$ & $\begin{array}{l}0.93(0.774) \\
1.06(0.685) \\
0.68(0.057) \\
0.92(0.488)\end{array}$ & $\begin{array}{l}0.63(0.031) \\
0.81(0.084) \\
1.12(0.329) \\
0.91(0.314)\end{array}$ & $\begin{array}{l}0.58(0.067) \\
1.05(0.754) \\
1.30(0.062) \\
1.07(0.568)\end{array}$ & $\begin{array}{l}1.02(0.936) \\
0.56(0.002) \\
1.22(0.176) \\
0.90(0.369)\end{array}$ \\
\hline $\begin{array}{l}\text { Psoriasis } \\
\quad 0-7 \mathrm{~km} \\
7-20 \mathrm{~km} \\
20-30 \mathrm{~km} \\
30-40 \mathrm{~km}\end{array}$ & $\begin{array}{l}1 \\
1 \\
1 \\
1\end{array}$ & $\begin{array}{l}0.92(0.759) \\
1.29(0.097) \\
0.90(0.664) \\
1.19(0.173)\end{array}$ & $\begin{array}{l}1.74(0.005) \\
1.11(0.511) \\
1.06(0.812) \\
1.04(0.766)\end{array}$ & $\begin{array}{l}0.89(0.563) \\
0.86(0.237) \\
1.27(0.106) \\
0.88(0.208)\end{array}$ & $\begin{array}{l}1.49(0.069) \\
1.11(0.501) \\
1.24(0.291) \\
1.06(0.672)\end{array}$ & $\begin{array}{l}0.81(0.474) \\
1.05(0.772) \\
0.94(0.797) \\
1.22(0.096)\end{array}$ \\
\hline $\begin{array}{l}\text { Urticaria } \\
0-7 \mathrm{~km} \\
7-20 \mathrm{~km} \\
20-30 \mathrm{~km} \\
30-40 \mathrm{~km}\end{array}$ & $\begin{array}{l}1 \\
1 \\
1 \\
1\end{array}$ & $\begin{array}{l}0.82(0.397) \\
1.17(0.220) \\
1.11(0.522) \\
1.11(0.522)\end{array}$ & $\begin{array}{l}0.96(0.848) \\
1.07(0.672) \\
0.97(0.868) \\
0.97(0.868)\end{array}$ & $\begin{array}{l}0.52(0.001) \\
0.75(0.009) \\
0.95(0.680) \\
0.95(0.680)\end{array}$ & $\begin{array}{l}1.16(0.472) \\
1.00(0.988) \\
0.96(0.791) \\
0.96(0.791)\end{array}$ & $\begin{array}{l}0.99(0.957) \\
1.02(0.897) \\
1.06(0.732) \\
1.06(0.732)\end{array}$ \\
\hline $\begin{array}{l}\text { Nevus } \\
\quad 0-7 \mathrm{~km} \\
7-20 \mathrm{~km} \\
20-30 \mathrm{~km} \\
30-40 \mathrm{~km}\end{array}$ & $\begin{array}{l}1 \\
1 \\
1 \\
1\end{array}$ & $\begin{array}{l}1.56(0.017) \\
1.24(0.162) \\
0.86(0.501) \\
1.06(0.688)\end{array}$ & $\begin{array}{l}0.87(0.170) \\
1.49(0.005) \\
1.50(0.022) \\
1.20(0.155)\end{array}$ & $\begin{array}{l}0.89(0.447) \\
0.80(0.082) \\
0.81(0.180) \\
0.87(0.164)\end{array}$ & $\begin{array}{l}1.11(0.655) \\
0.99(0.970) \\
0.99(0.972) \\
1.17(0.229)\end{array}$ & $\begin{array}{l}0.76(0.339) \\
1.07(0.677) \\
1.07(0.748) \\
1.01(0.928)\end{array}$ \\
\hline
\end{tabular}

*Estimates are adjusted to linear trend, annual and weekly seasonality; ${ }^{* *}$ Estimates express a multiplicative effect of the time period at study as compared to the non-military time. 
the two post-military weeks. As the skin disorders do not impose an immediate risk to the patients' life, the actual use of medical services could have been postponed by weeks. The pattern of decreased utilization of health services is likely to be attributed to the malfunction of the health services during military operations.

The military operations imply an obvious stress on the public, possibly triggering exacerbations of chronic skin disorders. Nevertheless, the study findings in fact contradict this hypothesis by adding to the uncertainty around this theory. ${ }^{14}$

In spite of being generally non-acute, skin disorders, may inflict a great deal of pain and personal discomfort and substantially contribute to reduction in health-related quality of life. ${ }^{15}$ A postponed professional attention, diagnosis and treatment may result in a more severe disease that, in turn may result in extensive destruction of skin architecture, scarring, impaired health status and professional life, and even higher number of concomitant systemic disorders as seen in acne ${ }^{16}$ and hidradenitis supporativa. ${ }^{17}$ The health practitioners have to be aware of alarming situations of this kind and take necessary measures to prevent possible exacerbations in case of a national crisis. This has become especially evident in the midst of the recent COVID-19 pandemic, when the health systems in most countries had to rapidly adjust to providing routine care to citizens under strenuous conditions of a worldwide crisis. This included online consultation, teleconferencing, telemedicine and medication online approvals, prescriptions and delivery. ${ }^{18,19}$

The study benefited from an access to the data on the large population consisting of civilians exposed to the military operations. There are several limitations to this study. For instance, purchasing of medications, one of the main outcomes measured in the study, is not highly specific to a certain disease, since some of them can be prescribed for other skin conditions. Hence, there is a possibility of a non-differential misclassification bias. Likewise, the eco- logical design of the study does not allow drawing causal conclusions based on the study findings.

\section{Conclusions}

We demonstrated a decrease in utilization of health services during the military operations in Israel. Although non-urgent in their majority, the routine care should not be delayed to prevent more serious skin conditions.

\section{References}

1. Kadir A, Shenoda S, Goldhagen J, et al. The Effects of Armed Conflict on Children. Pediatrics 2018;142: e20182586.

2. Lafta RK, Al-Nuaimi MA. War or health: a four-decade armed conflict in Iraq. Med Confl Surviv 2019;35:20926.

3. Muhjazi G, Gabrielli AF, Ruiz-Postigo JA, et al. Cutaneous leishmaniasis in Syria: A review of available data during the war years: 2011-2018. PLoS Negl Trop Dis 2019;13:e0007827.

4. Levy BS, Sidel VW. Documenting the Effects of Armed Conflict on Population Health. Annu Rev Public Health 2016;37:205-18.

5. Kimyai-Asadi A, Usman A. The role of psychological stress in skin disease. $\mathrm{J}$ Cutan Med Surg 2001;5:140-5.

6. Hall JM, Cruser D. Psychological Stress and the Cutaneous Immune Response: Roles of the HPA Axis and the Sympathetic Nervous System in Atopic Dermatitis and Psoriasis. Dermatol Res Pract 2012;2012:403908.

7. Cvitanovic H, Jancic E, Influence of stressful life events on coping in psoriasis. Coll Antropol 2014;38:1237-40.

8. Naldi L, Chatenoud L, Linder D, et al. Cigarette smoking, body mass index, and stressful life events as risk factors for psoriasis: results from an Italian case-control study. J Invest Dermatol 2005; 125:61-7.

9. Suárez AL, Feramisco JD, Koo J, Steinhoff M. Psychoneuroimmunology of Psychological Stress and Atopic Dermatitis: Pathophysiologic and Therapeutic Updates. Acta Derm Venereol 2012;92:7-15.

10. Arndt J, Smith N. Stress and Atopic dermatitis. Curr Allergy Asthma Rep 2008;8:312-7.

11. Misery L, Touboul S, Vinçot C, et al. Stress and seborrheic dermatitis. Ann Dermatol Venereol 2007;134:833-7.

12. Rajabi F, Drake LA, Senna MM, Rezaei N. Alopecia areata: a review of disease pathogenesis. Br J Dermatol 2018;179: 1033-48.

13. Chiu A, Chon SY, Kimball AB. The response of skin disease to stress: changes in the severity of acne vulgaris as affected by examination stress. Arch Dermatol 2003;139:897-900.

14. Snast I, Reiter O, Atzmony L, et al. Psychological stress and psoriasis: a systematic review and meta-analysis. Br J Dermatol 2018;178:1044-1055.

15. He Z, Marrone G, Ou A, et al. Factors affecting health-related quality of life in patients with skin disease: cross-sectional results from 8,789 patients with 16 skin diseases. Health Qual Life Outcomes 2020;4;18:298.

16. Pavlidis AI, Katsambas AD. Therapeutic approaches to reducing atrophic acne scarring. Clin Dermatol 2017;35:190-4.

17. Kokolakis G, Wolk K, SchneiderBurrus S, et al. Delayed diagnosis of hidradenitis suppurativa and its effect on patients and healthcare system. Dermatology 2020;236:421-30.

18. Shinkai K, Bruckner AL. Dermatology and COVID-19. JAMA 2020;324:1133-4.

19. Tao J, Song Z, Yang L, et al. Emergency management of 2019 novel coronavirus: implications for the dermatology department. Br J Dermatol 2020;182: e195. 